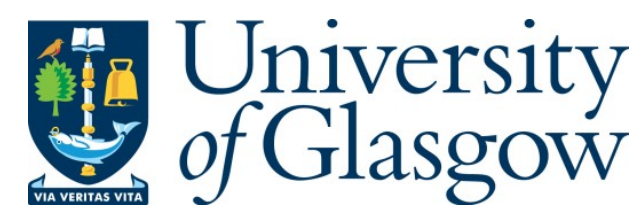

B ain, D. (2013) Pains that don't hurt. A ustralasian J ournal of Philosophy . ISSN 0004-8402

Copyright $\odot 2013$ Taylor and Francis

A copy can be downloaded for personal non-commercial research or study, without prior permission or charge

Content must not be changed in any way or reproduced in any format or medium without the formal permission of the copyright holder(s)

When referring to this work, full bibliographic details must be given

http://eprints.gla.ac.uk/82688/

Deposited on: 11 February 2014

Enlighten - Research publications by members of the University of Glasgow http://eprints.gla.ac.uk 


\section{Pains that Don't Hurt}

Forthcoming in Australasian Journal of Philosophy

The final version is available at:

www.tandfonline.com/doi/abs/10.1080/00048402.2013.822399\#.Uvk9cjZ_vQs

Abstract. Pain asymbolia is a rare condition caused by brain damage, usually in adulthood. Asymbolics feel pain but appear indifferent to it, and indifferent also to visual and verbal threats. How should we make sense of this? Nikola Grahek thinks asymbolics' pains are abnormal, lacking a component that make normal pains unpleasant and motivating. Colin Klein thinks that what is abnormal is not asymbolics' pains, but asymbolics: they have a psychological deficit making them unresponsive to unpleasant pain. I argue for a third view. Asymbolic pains are indeed abnormal, but they are abnormal because asymbolics are. I agree with Klein that asymbolics are incapable of caring about their bodily integrity; but I argue against him that, if this is to explain not only their indifference to visual and verbal threat, but also their indifference to pain, we need to do the following: (i) take asymbolics' lack of bodily care not as an alternative to, but as an explanation of, their pains missing a component; (ii) claim that the missing component consists in evaluative content. Asymbolia, I conclude, reveals not only that unpleasant pain is composite, but that its "hedomotive" component is evaluative.

Consider Norm and Abe. Norm is normal but Abe has been a pain asymbolic since a recent stroke. When we immerse their hands in scalding water, both say they feel pain, but Norm withdraws his hand, grimaces, and resents us, whereas Abe leaves his hand immersed, says he doesn't mind, and laughs. Unlike pain insensitives, Abe appears to feel pain; but unlike Norm, he seems indifferent to it.
What does Abe's case tell us about pain? I argue it tells us something not only about the relationship among pain, its unpleasantness, and its motivational force, but about the much-disputed nature of pain's unpleasant, motivational aspect. In particular, it corroborates the view that unpleasant pain's hedomotive component (as I call it) is evaluative (Author).

\section{Three Views of Asymbolia}

The little that philosophers have said about asymbolia typically conforms to one of two models. On the first, Abe's situation is as if a security system detects an intruder but fails to sound the alarm; on the second, it is as if the alarm sounds but no one responds (Fox 2012). The former, hedonic story says that Abe's pain is abnormal, being neither unpleasant nor motivational. Normal pain, it is claimed, is a composite of a neutral pain and a hedomotive component that contributes the overall state's unpleasantness and motivational force. Abe's pain lacks that component (Grahek 2007). By contrast, the non-hedonic, psychological story says that what is abnormal is not Abe's pain, but Abe. His pain is just as unpleasant as Norm's but fails to motivate him thanks to a psychological deficit of his: an abnormally high tolerance of unpleasantness, for instance, or as Colin Klein thinks, an incapacity to care about his body (2012). On this view, understanding asymbolia does not require a composite conception of unpleasant pain, since Abe's is a case not of pain without unpleasantness, but of unpleasantness without motivation, and the motivation is missing only because of a defect of Abe's.

I shall argue that each story has something right, but that neither is adequate as it stands. I agree with the non-hedonic story that one difference between Abe and Norm's cases is psychological. In particular, I think with Klein that Abe's lacking the capacity to care about his body would illuminate bizarre behaviour that the standard hedonic story neglects. But, against Klein, I argue that we leave Abe's other bizarre behaviour-his defective pain reactions-unexplained unless this carelack hypothesis is advanced not as an alternative to the idea that his pain is missing its hedomotive component, but as an explanation of why it is missing that component. So I also agree with the hedonic story: a crucial 
difference between Abe and Norm's cases is hedonic-hence, I claim phenomenal. In short, Abe's pain is abnormal because he is.

So my view is both psychological and hedonic. It is also evaluativist. For I argue that care-lack explains Abe's pain's missing hedomotive component only given the following:

\section{Evaluativism}

Being in unpleasant pain consists in (i) undergoing a somatosensory experience that represents (accurately or not) that a part of one's own body is damaged or under threat of damage; and (ii) that experience additionally representing the damage or threat as bad. ${ }^{1}$

On this view, the phenomenal character distinctive of pain experiences consists not in blank sensation or acquaintance with sense-data, but possession of the right representational content. Crucially for present purposes, a pain's inherently hedonic and motivational character (its unpleasantness and power to motivate damage-avoidance) consists in a layer of evaluative content, in virtue of which it represents states of damage as bad. That is the hedomotive component that I think Abe's pain lacks. ${ }^{2}$ Now, it is not the job of this paper to defend evaluativism; that is a task I have begun elsewhere (Author). My point here is that we cannot realise the explanatory potential of the care-lack hypothesis without evaluativism. If evaluativism is defensible, it illuminates asymbolia.

Beyond its intrinsic interest, then, and the general significance of the idea of bodily care, asymbolia is important for two reasons: it reveals unpleasant pain to be composite and, more surprisingly, it suggests that its hedomotive component is evaluative. I argue for these claims in §§6-7, before which I consider three alternative accounts: one hedonic, two nonhedonic. But first we must get clearer about the data and desiderata.

\section{Data and Desiderata}

${ }^{1}$ See Author, Cutter and Tye 2011, Helm 2002, and \$\$6-7 below.

${ }^{2}$ Like other necessary a posteriori identity claims (e.g. that visual experiences' red-feeling character is their red-representing content), evaluativists face the objection that the identified features dissociate. For two such charges, see objections 3 and 4 in $\$ 7$ below.
Erwin Stengel and Marcelo Berthier provide the clearest case studies of asymbolia. $^{3}$ Stengel discovered the condition in 1928, with Paul Schilder, and published studies of it until 1940; Berthier analysed another six cases in 1988. Stengel and Berthier's patients typically had lesions to their insular cortex, resulting from strokes or brain tumours in adulthood. ${ }^{4}$ Given noxious stimuli, such as pinches, pinpricks, electric shocks, and hot and cold water, they responded as follows:

1. Avoidance and approach. All of Berthier's patients exhibited a "total lack of withdrawal", occasionally resulting in serious injury outside the laboratory (1988: $42-43,46)$. Stengel reports that withdrawal was either absent or slow and incomplete (1928: 147).

2. Verbal behaviour. Berthier's patients reported no unpleasantness (1988: 43, 47). Some said the stimuli didn't "bother" them or were "nothing" (Pötzl and Stengel 1937: 180).

3. Expressive Behaviour. Despite the noxious stimuli, Berthier reports that none grimaced or winced (1988: 43). (Some smiled and laughed.)

4. Emotional reaction. The patients were cooperative, and not anxious or angry about the tests (Berthier et al 1988: 43; Schilder and Stengel 1928).

These deficits invite the conclusion that asymbolics are pain insensitives, incapable of pain. But I agree with Stengel and Berthier that they are not, since asymbolics say they feel pain, even speaking of stimuli hurting them and being painful, ${ }^{5}$ which testimony is the more significant given further differences between them and classical insensitives: (i) they feel and react

${ }^{3}$ For their co-authors, see bibliography.

Berthier et al 1988 (41, 47); Schilder and Stengel 1928, 1931.

${ }^{5}$ Schilder and Stengel 1928 (147); Berthier et al 1988 (44); Pötzl and Stengel 1937 (180). 
to pain normally for many years before becoming asymbolics, (ii) they appear to grasp the concept pain, (iii) their peripheral nervous systems are intact and functioning, and (iv) their autonomic responses to noxious stimuli (e.g. increased heart rate and sweating) are also normal. ${ }^{6}$ Hence call the listed deficits the pain deficits, since they involve not an absence of pain, but a failure to respond to it normally.

But the pain deficits are only half the story. Not all asymbolic behaviour looks like abnormal responses to pain, for asymbolics also exhibit what I call the non-pain deficits:

5. Learning. Stengel and Berthier's patients appeared even worse than pain insensitives at learning which circumstances require avoidance behaviour (Berthier et al 1988: 41-43; Klein 2012).

6. Self-harm. Stengel and Berthier's patients sometimes approached noxious stimuli, for example placing their fingers in flames (Schilder and Stengel 1928: 149). One pricked herself and jammed objects into her eyelids (Schilder and Stengel 1931: 598).

7. Visual and auditory threats. The patients failed to respond to visual and auditory stimuli of a salient or threatening kind. When investigators came at them with hammers, knives, and needles, they didn't respond fearfully or aversively. One of Hemphill and Stengel's patients was almost run over because, although he recognised a noise as the horn of a lorry bearing down on him, he failed to respond. ${ }^{8}$

' See, on (i), Berthier et al 1988 (44); on (ii), Trigg 1970 (70-72); on (iii), Nagasaki 2003 (214); on (iv), Berthier et al 1988 (44).

${ }^{7}$ On whether these might be explained by the pain abnormalities, see $\$ 3$.

${ }^{8}$ Berthier et al 1988 (42); Schilder and Stengel 1931 (598); Schilder and Stengel 1928 (149);

Hemphill and Stengel 1940 (256-57, 259).
8. Verbal threats. The patients didn't respond to verbal threats. When warned of noxious stimuli, all but one of Berthier's patients did nothing (1988: 42-43). ${ }^{9}$

Now, the pain and non-pain deficits are surely not a motley. They exhibit a consilience, which Stengel characterises as a failure to appreciate "any threats in general" (Schilder and Stengel 1928). Hence I shall count it a virtue of an explanation of asymbolia that it speaks to this consilience, and that it explains why pain and non-pain deficits tend to co-occur in asymbolics. Accounts that explain, simply and without adhockery, not only why asymbolics are unresponsive to pain, but why they are unresponsive to visual or verbal threats, for example, are ceteris paribus preferable to accounts that don't. But explanations must not be too broad. It won't do, for instance, to say asymbolics cannot feel any negative emotions, since there is evidence they can. ${ }^{10} \mathrm{I}^{\prime} \mathrm{ll}$ call this challenge, of speaking to both the pain and non-pain deficits, without predicting deficits that asymbolics lack, the scope challenge. It plays an important role below. (Author):

I shall also take the following to be worth preserving if possible

PU. Necessarily, all pains are unpleasant

UM. Necessarily, unpleasant pains are inherently motivational, i.e. such as to defeasibly motivate damage-limitation, independently of further desires.

It might seem as though hedonic accounts must reject PU and nonhedonic accounts UM. We shall see whether that is so.

Finally, a caveat. Although I shall proceed as though Abe were an exemplar of a well attested condition, the condition (if there is one) is considerably less well attested than one would wish (Fox 2012). Detailed case studies are old and few, and they report exceptions: one of Berthier's patients responded to visual threats; one of Stengel's grimaced. Moreover,

Schilder and Stengel 1928 (154).

${ }^{10}$ Schilder and Stengel 1928; Hemphill and Stengel 1940 (256). 
while Stengel, Berthier, and I count subjects as asymbolics only if they claim to feel pain, other theorists' require only weaker evidence of pain, and yet others don't require any, either not recognising a distinction between pain insensitivity and indifference, or recognising it but using the term "asymbolia" for a kind of insensitivity. It might be, then, that the literature categorises multiple conditions as asymbolia. Given all this, my conclusions should be regarded as tentative only, and as having the following form: if there is a condition of which Abe's case is paradigmatic, here is what we should say about it.

\section{Grahek's Hedonic Account}

As an hedonic theorist, Nikola Grahek claims that Abe's pain is missing its hedomotive component. This requires a composite view of unpleasant pain. My evaluativism is one such view. Another is Pitcher's, on which the hedomotive component is not an evaluation of represented damage, but a desire for the damage-representation to cease:

\section{Desire View}

Being in unpleasant pain consists in (i) undergoing a somatosensory experience that represents (accurately or not) that a part of one's own body is damaged, or under threat of damage; and (ii) having a non-instrumental desire for that experience immediately to cease. (Pitcher 1970)

Grahek endorses a third composite view:

\section{Damage View}

Being in unpleasant pain consists in (i) undergoing a somatosensory experience that represents (accurately or not) "the location, intensity, temporal profile, and nature of a harmful stimulus" (Grahek 2007: 2); and (ii) that experience additionally representing the stimulus as damaging, or threatening damage (2007: 80). ${ }^{11}$

On this view, pain's damage-representing content constitutes not the neutral but the hedomotive component. So it is this content that Grahek thinks Abe's pain lacks (2007: 80-83). But for now these details don't matter. Whichever composite view the hedonic theorist opts for, the question is: does the idea that Abe's pain is missing its hedomotive component illuminate Abe all by itself?

I think not. For this basic hedonic view, as it stands, fails the scope challenge. ${ }^{12}$ While it explains Abe's pain deficits, it neglects his nonpain deficits. Why does Abe not withdraw from visual or verbal threats, for example? Why is he worse than insensitives at learning how to avoid injury? That his pains are missing their hedomotive component provides no answer.

At one point, Grahek gestures at a more general thesis: that asymbolics' lesions disconnect their sensory and limbic systems, making them incapable of "attach[ing] appropriate emotional significance to painful stimuli" (Grahek 2007: 52). ${ }^{13}$ If "painful stimuli" is taken as "any sensory representation of noxious stimuli", this might seem to broaden his account so as to capture Abe's visual and auditory deficits. But whatever the view's other merits, it leaves other non-pain deficits unexplained. Why, for example, is Abe unresponsive when told he is to be injured? And why is worse than insensitives at learning how to avoid injury?

Another reply Grahek gestures at is that only brains capable of unpleasant pain will store certain associations. Perhaps Abe doesn't respond to visual threat, for example, simply because he knows it won't cause unpleasant pain. But that explanation would work only if people

${ }^{11}$ Grahek is hard to interpret and might not endorse precisely this, since he seems to think that the neutral pain (and perhaps the hedomotive component) also has non-representationt phenow pais phenomenal quatties (2007: 81, 95-96). He is cettainly a composite theorist, however, which makes him valnate to my objections. He also says that, "pointing to nothing beyond itself" $(2007: 76,80)$, the neutral pain lacks "representational ... force". But I take his point to be only that the pain's "pain quality" fails to represent (2007: 95-96). Grahek occasionally sounds rather evaluativist, as where he denies that the hedomotive component is "a coldly calculated informational appraisal" (2007: 80; see also 82, 89, and 92).

${ }^{12}$ Klein 2012.

${ }^{13}$ See also Geschwind 1965 and Berthier et al 1988 (48). 
avoided damage only to avoid unpleasant pain, which the case of pain insensitives - who don't feel pain but still try to avoid damage-shows is false (Klein 2012). Grahek might reply that Abe's brain won't associate visual threat even with damage. He reminds us that there are neurons whose response rate, given visual presentations of a pin approaching the subject's face, declines until the pin makes contact-as though unpleasant pain (which Grahek takes to be damage-representing) is required to "remind" the brain of the association between the visual threat and such damage (2007: 68). Abe's problem, the idea goes, is that his brain cannot be thus "reminded". Now, this explanation arguably predicts a delay that the literature does not report: between the onset of Abe's pain deficits and his visual deficits. But that might be the literature's fault, not the view's. A more serious difficulty is that it leaves certain non-pain deficits unexplained (Klein 2012). Why, for instance, does Abe not respond when told he is to be injured? Here we might appeal to yet more associations, involving utterance types. But the problem persists: an otherwise normal subject should, as a matter of practical rationality, take evasive action when warned of damage even if his brain has "forgotten" such associations. Yet Abe does not. Indeed, he sometimes inflicts damage on himself. Why?

So the basic hedonic account fails the scope challenge, and Grahek's associationist elaborations don't help. For all this, I shall ultimately endorse an hedonic account, one that substitutes my composite view for Grahek's and incorporates the care-lack hypothesis. But why bother? Why not opt for a non-hedonic, psychological story?

\section{U-Tolerance: a Non-Hedonic Psychological Account}

According to the non-hedonic, psychological story, recall, Abe's pain is just as unpleasant as Norm's, but he fails to react thanks to some psychological deficit. One such view says the psychological deficit is an abnormally high tolerance of pain's unpleasantness. Abe, as we might put it, is more $u$-tolerant than Norm. U-tolerance must be distinguished from what I call stimulus thresholds, for example the minimum stimulus intensities a subject will say cause pain or are intolerable. ${ }^{14}$ These

${ }^{14}$ Berthier et al $1988(42,44)$. thresholds don't help: Abe and Norm categorise the same intensities as pain-causing; and while there is no intensity Abe will call intolerable, that's our explanandum, not an explanation. But u-tolerance is a different: it is the minimum degree not of stimulus intensity, but of unpleasant pain, that a subject will call intolerable. And this seems more promising. Enjoying higher $\mathrm{u}$-tolerance, Abe is simply tougher than Norm.

This account preserves PU more easily than Grahek's. And it seems to cohere with what some asymbolics say, for example those who report that noxious stimuli "hurt", ${ }^{15}$ and the patient of Stengel's who puts his own deficits down to being "used to" pain after a lifetime of labouring (Hemphill and Stengel 1940: 256). But the proposal also has difficulties, not least how to make sense of $\mathrm{u}$-tolerance in such a way as to make sense of Abe.

What might it mean to say that Abe is more tolerant of pain's unpleasantness than Norm? Perhaps that he is made less anxious by a given degree of unpleasant pain. If so, asymbolia resembles lobotomy for chronic pain in so far as lobotomy reduces neither the patient's pain nor its unpleasantness, but only her anxiety about the pain and its significance (Price 2000). But, while Abe is indeed less anxious than Norm, he doesn't look merely less anxious. For instance, while the lobotomised still withdraw and wince at novel pains caused by pinprick, ${ }^{16}$ Abe doesn't. The current proposal fails to say why.

A second elaboration of Abe's u-tolerance is twofold: (i) pain's unpleasantness normally motivates only because we normally want it to cease; (ii) Abe's lesions prevent that desire. But this is hard to swallow given the conflict between (i) and the intuition, UM, that pain's unpleasantness is inherently motivating. To see this, notice how much less plausible (i) is than Pitcher's desire view. Whereas Pitcher thinks subjects' anti-pain desires make their pains motivating and unpleasant, so if one lacks such a desire then one's pain is neither motivating nor unpleasant, (i) says that subjects' anti-unpleasantness desires make independently unpleasant pains motivating, so if one lacks such a desire then one's pain is not even defeasibly motivating even though it is still

${ }^{15}$ Schilder and Stengel 1928. Berthier et al 1988 says asymbolics have pain thresholds, defined as the minimum stimulus intensities subjects call "painful".

${ }^{16}$ Melzack and Wall 1982 (131). 
unpleasant. Some bullets must be bitten, of course, but I shall show that our best account of asymbolia needn't bite this one.

In parallel with metaethical internalism, UM must of course be reconciled with two possibilities: a pain's motivational force being defeated by stronger motivations, and a completely paralysed person suffering unpleasant pain (Author). But if it is therefore suggested that Abe is u-tolerant simply in the sense that his pain's motivational force is always defeated, we must be told what the defeating motivations are. It might instead be suggested that he is u-tolerant in the sense that he is paralysed-not generally, of course, but in a way limited to the behavioural effects of unpleasant pain. But even were we to accept this, it would leave two crucial things unexplained: Abe's non-pain deficits, and his denial that his pain is unpleasant.

That last point is crucial, for the same two problems will surely undermine all $\mathrm{u}$-tolerance accounts, including a final primitivist version, which says u-tolerance consists simply in finding pain's unpleasantness relatively, well, tolerable. For even were we prepared to accept such primitivism, the two problems just mentioned remain. How does tolerance of pain's unpleasantness explain Abe's unresponsiveness to visual and verbal threat? And if his pain is unpleasant, why does he say it isn't? It might be said that all he means is that his pain, while unpleasant, is tolerable. But I shall show we can do better than that.

\section{Klein's Non-Hedonic Psychological Account}

Colin Klein has recently proposed another non-hedonic, psychological approach. ${ }^{17}$ Crucially, it promises to do what both u-tolerance and Grahek's hedonic approach failed to do: namely, explain Abe's non-pain deficits. For the psychological abnormality Klein attributes to Abe is not u-tolerance, but an inability to care about his own body; and this explains Abe's non-pain deficits nicely. Why is Abe unresponsive to visual and verbal threats of bodily harm? Why does he seem worse than pain insensitives at learning which situations might harm him? Why does he sometimes harm himself? Because, Klein says, there is a basic kind of care

${ }^{17}$ In correspondence, Klein accepts that his is a non-hedonic account. for one's own bodily integrity that Abe-thanks to his brain damagelacks.

But Klein's view faces three serious difficulties. The first two are faced by all non-hedonic accounts, and are familiar from our discussion of u-tolerance. First, if Abe's pain is unpleasant, why does he fail to grimace and say that it isn't? Klein might wiggle and say that Abe only means that, while unpleasant, his pain doesn't motivate damage-limitation behaviour. But not only is that a stretch, it leaves his failure to grimace unexplained.

Second, Klein arguably struggles to accommodate UM, the idea that pain's unpleasantness is inherently motivating. Klein claims, on the contrary, that his care-lack view accommodates pain's motivational force better than hedonic views. For he thinks the reason Abe's unpleasant pain fails to motivate him is not that his pain is defective, but that he is. Just as a struck match might have the power to light yet not do so if oxygen is absent, so Abe's pain has everything it needs to motivate-defeasibly and absent physical impediments - but fails to do so only because Abe fails to care, care being an enabling condition on the pain's motivational power. But I still insist that hedonic views better accommodate pain's motivational force. Yes, they say Abe's pain is missing something, but that doesn't violate our intuitions about pains' motivational force, since what they are missing is precisely what intuitively makes pains motivational: namely, their unpleasantness. To put it another way, if hedonic views violate an intuition, it is PU, not UM. It remains the case, moreover, that Klein imposes an enabling condition on an unpleasant pain's motivating its subject that my hedonic view does not: that the subject care about his bodily integrity. For I shall argue that such care is a condition not on unpleasant pain motivating, but on a pain's being unpleasant.

Third, and most important, while Klein explains the non-pain deficits, he does so at the cost of failing to explain the pain deficits. I have already mentioned two such deficits: Abe's denial of his pain's unpleasantness and his failure to grimace. But the problem is more general. Why does Abe not withdraw when caused pain? Why, when in pain, does he not exhibit anger or anxiety? The official answer is that Abe is incapable of caring about his bodily integrity. But that just postpones the problem, for why should lack of care matter? Why should care be an 
enabling condition on the motivational force of one's pain? Call that the relevance question. And notice it won't do to reply that Abe of course won't be motivated by his pains if he doesn't care about them. For the care-lack view is that Abe cannot care about his body, not about his pains. In a sense, it is true, he doesn't care about his pains; but that is our explanandum, not an explanation. So the relevance question remains.

We might hope an answer would come from Klein's imperativist view of the nature of pain's motivational character:

\section{Klein's unitary imperativism}

Being in unpleasant pain consists in undergoing an experience with a non-indicative, imperative content, in virtue of which the experience commands one to stop doing what one is doing.

On this view, unpleasant pains are unitary, not composite, and they motivate in virtue of their imperative content. One is motivated to stop putting weight on one's sprained ankle because one's pain tells one to. Does this answer the relevance question? I think not. Suppose, as Klein does, that imperative contents are normally motivating. It is quite unclear why Abe's not caring about his body should make them any less so. Klein might say that their content is not purely imperative: not "Stop putting weight on your ankle!", but "Stop putting weight on your ankle or else it will get damaged!". But that will help only given the following idea: while the italicised, indicative warning of bodily damage normally motivates, it fails to do so in Abe's case because of care-lack. Yet that would undermine Klein's imperativism, for imperativism's central idea is that since indicative content is motivationally inert, pains must have imperative content. So an imperativist better not rest the care-lack explanation on the motivational power of indicative rather than imperative contents.

\section{An Hedonic and Psychological Account}

Despite the difficulties besetting Klein's care-lack account, I don't want to jettison his idea that Abe lacks care, given its explanatory promise. It alone looks capable of explaining Abe's non-pain deficits. And Klein makes a persuasive case that it also dovetails with prevailing conceptions of the role of the insula, as well as illuminating intriguing similarities between the pain reactions of asymbolics, on the one hand, and those of schizophrenics, the depersonalised, and morphine patients, on the other (Klein 2012). But can the care-lack idea be elaborated in a way that avoids my objections?

I think it can, provided we do two things:

A. Reject Klein's unitary imperativism for a composite view, distinguishing neutral pains and hedomotive components.

B. Reject Klein's idea that care-lack disables unpleasant pain's motivational force, and claim instead that carelack prevents pain's unpleasantness altogether. Hold, in other words, that care is an existence condition on pain's unpleasantness, not an enabling condition on its motivational force.

Most conceptions of pain's unpleasantness, I'll presently argue, block B. But if the obstacles can somehow be avoided, the prize will be a view that is both psychological and hedonic, a view on which Abe's pain lacks unpleasantness because he lacks care-again, on which his pain is abnormal because he is. This preserves the strengths of Klein's account without the weaknesses. It preserves his explanation of Abe's non-pain deficits in terms of care-lack. And, taking care-lack to prevent-not merely disable-Abe's pain's unpleasantness, it also does what Klein couldn't do: explain Abe's pain deficits, for example his failure to withdraw, his failure to grimace or get angry, and his denial that his pain is unpleasant. It does so, moreover, while straightforwardly capturing UM. For we need not impose Klein's enabling condition on unpleasant pains motivating if we can instead say that the reason Abe's pain fails to motivate is that it is not unpleasant. 


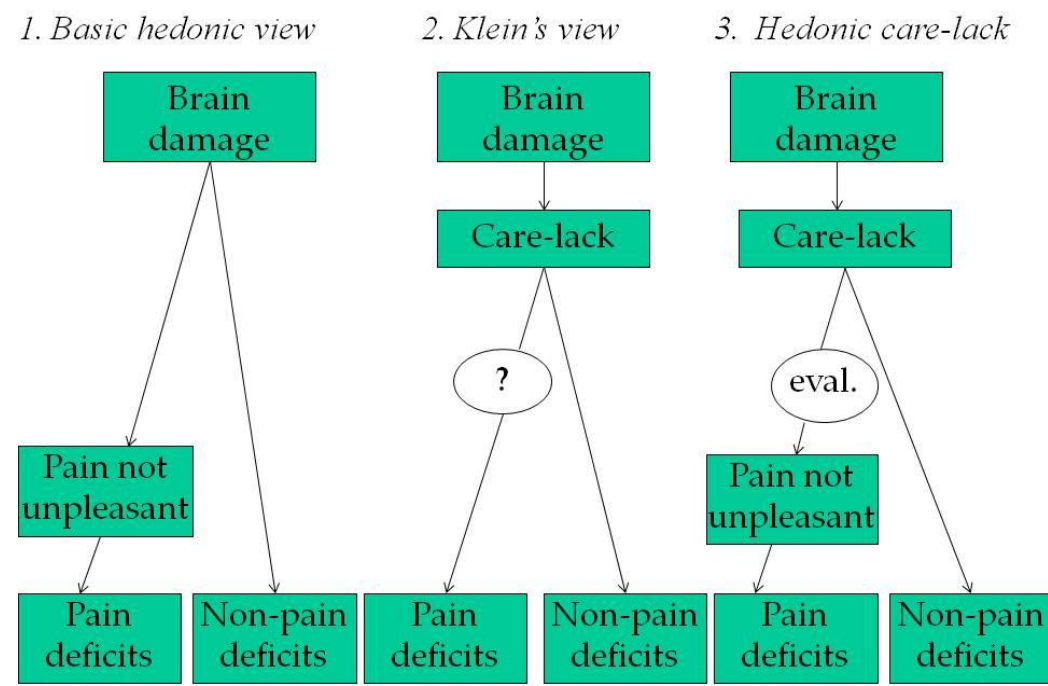

So the prize is attractive. But the relevance question remains, albeit in a new guise: why should a lack of bodily care prevent pain's unpleasantness?

As a unitary imperativist, Klein has no answer. But what about composite imperativists, such as Richard Hall and Manolo Martínez, who hold that unpleasant pain's content comprises a neutral, indicative component, and an hedomotive, imperative component (Hall 2008; Martínez 2011)? Applying this to Abe, in line with A and B, the idea would be that Abe's not caring about his bodily integrity prevents pain's imperative content. But the question remains: why should it do that? Imperativists have no answer. Hence imperativism, I suggest, has now been shown to be incapable of capitalising on the care-lack hypothesis whether it is elaborated in Klein's way or in mine.

Pitcher's desire view also doesn't help. Pitcher thinks that an unpleasant pain's hedomotive component is a desire for the pain to cease. Applying this to Abe, in line with $\mathrm{A}$ and $\mathrm{B}$, the idea would be that Abe's care-lack prevents this desire. But why should it? Why should Abe's not caring about his body prevent him from wanting his pain - an experienceto cease?

Grahek's composite account doesn't help either. He thinks that pain's hedomotive component consists in a layer of damage-representing content. ${ }^{18}$ Applying this to Abe, in line with A and B, the idea would be that Abe's care-lack prevents the damage-representing content. But why should it? You might not care about an orchid and yet believe that the dry weather is damaging it; so too Abe might fail to care about his own body yet still have an experience representing it as damaged. Care, in short, doesn't look like an existence condition even on experiential damagerepresentations. The Grahekian might instead say that it is an enabling condition, that Abe's care-lack doesn't prevent but merely disables his pain experience's damage-representing content, hence its unpleasantness. But that would make the care-lack account a non-hedonic view, hence vulnerable to objections I made in $\S \S 4-5$ : namely, that it cannot explain why Abe denies his pain is unpleasant and fails to grimace; and that it distances pain's unpleasantness from motivation.

There is a better way. What is needed to capitalise on A and B is the composite view I introduced at the outset. For evaluativism answers the relevance question. Why should pain's hedomotive component rely on the subject's caring about his bodily integrity? Because, I suggest, unpleasant pain's hedomotive component consists in an evaluative layer of content by dint of which it represents states of damage as bad; and it will present those states in that way only to a subject who cares about his body. This, I suggest, is highly plausible. I concede-indeed I insist-that bodily states could strike Abe as damaging even while he fails to care about his body. But, if he doesn't care about his body, they won't strike him as bad, hence won't be unpleasant, hence won't motivate avoidance behaviour. Evaluativism, I suggest, thus answers the relevance question. ${ }^{19}$

Unpleasant pains are not the only evaluations that depend on a given kind of care. Consider fear. Though you and I both watch a rock

${ }^{18}$ If unpleasantness instead consists in non-representational qualia, as Grahek sometimes seems to think (see note 11 above), the relevance question would be even harder to answer.

${ }_{19}$ The point is not that "pain's unpleasantness = pain's possession of the right evaluative content" holds only for those who care, but that pains will have that content, hence be unpleasant, only in those who care. 
falling towards a vase, it might be that only you fear it because only you care about the vase. ${ }^{20}$ Why might care make this difference? Because, I suggest, fear too is evaluative, representing the danger that $\mathrm{x}$ poses to $\mathrm{y}$ as bad, and one's experientially representing the danger posed to $\mathrm{y}$ as bad requires one to care about $y$. Hence this contrast between you and me in the fear case is much like the contrast I am drawing between Norm and Abe in the pain case: they both have pain experiences representing their bodies as damaged, but only Norm cares about his body, hence only his pain represents the damage as bad, hence only his pain is unpleasant and motivating.

So whereas Klein claims that Norm differs from Abe in caring about his body, I am insisting on a further difference. The difference is not doxastic. It is not that only Norm believes his body to be in a bad state. Apart from anything else, Norm might lack that belief if he were an allodyniac, susceptible to unpleasant pains caused by innocuous touch The difference on which I am insisting is rather a difference in perceptual content. Only Norm's pains represent his body as being in a bad statewhich, notice, doesn't require him to believe that it is. This difference, moreover, determines an hedonic and phenomenal difference. Things feel different to Abe and Norm: Norm's pain is unpleasant, Abe's is not. That is why Abe denies it is unpleasant and fails to grimace, and why his pain doesn't motivate avoidance behaviour. Thus the pain deficits are explained. But, crucially, I also hold that what underlies this difference in perceptual content is a difference in bodily care, which difference-just as Klein says-also explains Abe's non-pain deficits. Hence the scope challenge is met at last. And it is met while respecting UM, since on this account care is a condition not on unpleasantness motivating, but on a pain being unpleasant.

\section{Objections}

In closing, I briefly consider six objections.

${ }^{20}$ The example is Helm's (2002). He takes a similar view of pain to mine but ignores pain asymbolia and seems to resist the idea that unpleasant pain has the composite structure I think is essential to explaining it.
Objection 1. Why is preserving UM but violating PU (as my account does) more attractive than preserving PU but violating UM (as Klein's does)?

Although I've said that Abe has a pain that is not unpleasant, my account could be reformulated so as to pay lip service to PU. Although I haven't, we might take the term "pain" to apply not to an unpleasant pain's neutral component, but only to the whole composite, and still take Abe's pain reports seriously by claiming he undergoes a neutral experience which (i) would have counted as a pain had it been accompanied by the usual hedomotive component, and (ii) is sufficiently distinctive of paradigmatic cases of pain to explain (if not vindicate) his pain report. To this extent, I can accommodate not only UM, but PU.

Some might take UM to be refuted by other counterexamples, hence deny that accommodating it is a virtue. ${ }^{21}$ But the putative counterexamples are far from conclusive. While the lobotomised say pain doesn't bother them, for instance, arguably they mean only that it doesn't make them anxious; and while masochists seem to seek pain, arguably their pain is either not unpleasant or its motivational force is present but defeated by stronger motivations, perhaps for humiliation. Moreover, and more important, I have anyway shown that my view has much more than $\mathrm{UM}$ to recommend it.

Objection 2. Even while indifferent about Beth's bodily integrity, Anne might believe that damage to Beth's body is bad. Evaluative content is not care-dependent. ${ }^{22}$

I concede that Anne might believe that a state of Beth's body is bad in various senses, for example that the state is one of damage, impeding the body's proper functioning; that the damage is severe; and that it is

${ }^{21}$ For more on UM (and PU) see Author. Note too that Corns (forthcoming) argues that "hedonic tone" and "aversive valence" doubly dissociate. But (i) the bearing of her argument on UM is debatable given she takes even unconscious states to have "hedonic tone"; (ii) UM allows anti-damage motivations to dissociate from unpleasant pains; and (iii) Corns concedes that examples of dissociation in the opposite direction are inconclusive.

${ }^{22}$ If we retreat to the idea that care is an enabling condition on such content's motivational force, we end up with a non-hedonic view, which faces now-familiar objections. 
contrary to Beth's interests. But such beliefs are not what evaluativism invokes to explain pain's unpleasantness. Evaluativism invokes episodes in which badness in another, fully normative sense is represented experientially, episodes in which the subject is struck that certain bodily states are, as we might put it, to-be-avoided. ${ }^{23}$ It is these episodes that carelack seems to prevent.

Setting my proposal in context, I earlier mentioned fear. But desire is another instructive case. Just as I have elsewhere argued for evaluativism on the basis that unpleasant pains can be motivating reasons-episodes that motivate behaviour in such a way as to allow sense to be made of it in terms of the reasons for which an agent performed it-only by dint of their being evaluative experiences, in which subjects are struck by the badness of their bodily states (Author), so others have similarly argued that desires can be motivating reasons only by dint of their being evaluative experiences, in which subjects are struck by the goodness of what is desired (Stampe 1987; Helm 2002; Oddie 2005). And some of these theorists' examples support the claim I am making here: that such evaluative experiences are care-dependent. Dennis Stampe, for instance, remarks that one might judge that something (e.g. the end of a war) would be good without being even defeasibly moved to bring it about, if one did not care sufficiently to "arouse" a desire for that thing-again, as Stampe also puts it, if one did not care sufficiently to produce "a perceptual state in which that thing seems good" (1987: 358-359). It is in much the same way, I am claiming, that Abe's care-lack prevents his pain experience from representing his bodily state as (in the relevant sense) bad. ${ }^{24}$

A full defence of evaluativism would need to speak to the metaphysics of badness. There are a range of options, from realism to eliminativism. But all I need here is that bodily states can perceptually seem bad in the relevant sense. I don't have a psychosemantics to prove they can; but nor do I see a compelling reason to insist they cannot. ${ }^{25}$

${ }^{23}$ See Oddie 2005 (42) and Helm 2003 (21).

${ }^{24}$ Helm similarly thinks that differences in "background concern ... for one's [own] safety and integrity" can explain differences between pleasant and painful experiences (2002: 16-17, 22-23). ${ }^{25}$ Cutter and Tye (2011) provide a "tracking" psychosemantics, but arguably identify damage and badness. For gestures at other accounts, see Helm on pain (2002: 23) and Stampe on desire (1987: 364-374).
Objection 3. Others who lack care (e.g. the lobotomised, the suicidal, and those who hate their bodies) nonetheless have unpleasant, motivating pains. So either evaluative content is not care-dependent or evaluativism is false.

In reply, I deny that the suicidal or those who hate their bodies lack care. To commit suicide is to override care for your body, not to lack it. Nor does hating how your body looks, or even being disgusted by it, involve lacking care for it. As for the lobotomised, one option is to say that their pains are not unpleasant and motivating. I earlier denied this (\$4) but there remains another option: that the lobotomised's lack of anxiety about their chronic pain reflects something other than a lack of care for their bodily integrity. And, given how much else the lobotomised are relaxed about, that option seems plausible.

Objection 4. If it is by dint of their evaluative content that pains are unpleasant and motivating, the same must be true of thirst sensations. Yet Abe has thirst sensations that motivate him to drink (Schilder and Stengel 1928: 150). So either evaluative content is not care-dependent or evaluativism is false.

The worry is that the care-lack hypothesis fails the scope challenge not by being too narrow (omitting some deficits) but by being too broad (predicting deficits Abe lacks). ${ }^{26}$ But there are three replies. First, we might resist extending evaluativism beyond pain to thirst. Second, we might demand more evidence before conceding the problematic datum: not that Abe drinks, but that he is driven to do so in the normal way by hedonic thirst sensations. Finally, we might distinguish kinds of bodily care. Abe, the idea would go, lacks the kind that underlies the hedomotive component of pain, but not the kind that underlies the hedomotive component of thirst. The former, perhaps, is care that one's body not be damaged (call this d-care), the latter is care that that its needs are met (n-care). Normal subjects, of course, both d-care and n-care, and

${ }^{26}$ A similar worry: if Abe doesn't care about his body, he should be more susceptible to injury than Norm. Reply: asymbolics are more injury-prone, so long as their asymbolia (which is not always permanent) lasts. See Berthier et al $1988(42-43,44)$. 
they n-care partly because they d-care, since unmet needs cause damage. But, the idea goes, Abe is brain damaged; and he is brain damaged in such a way as to prevent $\mathrm{d}$-care but not n-care, thus preventing the hedomotive component only of his pain, not of his thirst. ${ }^{27}$

Objection 5. D-caring is merely a matter of being motivated to avoid bodily damage. So the care-lack account amounts to the triviality that Abe is unmotivated to avoid bodily damage because he is unmotivated to avoid bodily damage.

But my version of the care-lack explanation of Abe comes to more than that. Norm's d-care is not merely a matter of his being inclined to avoid bodily damage. Rather, I suggest, it is a standing, non-episodic state, one that is non-conceptual yet itself evaluative. ${ }^{28}$ And, crucially, while this care state explains Norm's being motivated to avoid bodily damage, that is not all it explains. I have insisted it also explains his pain's unpleasantness, and thereby his grimacing and his resenting those who gratuitously cause him pain. So, I suggest, another advantage of meeting the scope challenge is that it heads off the threat of triviality.

Objection 6. Two final worries, about care and desire: (i) Care for one's bodily integrity entails a desire to avoid bodily damage; but unpleasant pain surely doesn't, since one can feel unpleasant pain without possessing concepts and while willingly sustaining bodily damage. (ii) If Abe doesn't care about his body, he lacks such an anti-damage desire, and that lack suffices to explain his failure to withdraw from noxious stimuli all by itself, rendering my appeal to a missing layer of evaluative content otiose.

To begin with (i), this much is true: I claim that care is required for damage to produce certain motivational episodes in a subject, namely unpleasant pains. But I am not committed to such care entailing anti-

${ }^{27}$ It might be felt that this is ad hoc, but there are independent reasons to distinguish kinds of

${ }^{28}$ See Helm 2002 on care as a standing evaluation. Regarding care's non-conceptuality, another option is to say it is conceptual but invoke some non-conceptual "proto-care" that plays a similar role in beings without concepts. Note that care is also not merely a disposition to have unpleasant pains when damaged. damage desires in any more demanding sense of "desire". Moreover, such anti-damage motivation as unpleasant pains entail is defeasible: it might be defeated by another motivation (e.g. to save one's family from the flames), driving one not to minimise damage.

Turning to (ii), the objector's idea is that we might locate the difference between Abe and Norm in Norm's anti-damage desires. But this poses a crucial question. Does this desiderative difference make for a hedonic, phenomenal difference? Suppose the objector says it does not. In that case, hers is a non-hedonic view, hence vulnerable to now-familiar objections: it distances pain's unpleasantness from motivation, since it says that, while Abe's pain is unpleasant like Norm's, it fails to motivate because of his missing desire; and it leaves unexplained why, if Abe's pain is unpleasant, he fails to grimace and says that it is not. In short, the difference between Abe and Norm looks hedonic and phenomenal, not merely desiderative.

Now suppose that the objector claims her proposed desiderative difference does constitute an hedonic, phenomenal difference. In that case, the view is not obviously a rival to mine. For my view too says that some care-dependent accompaniment of Norm's pain renders his pain motivating and unpleasant, and my view too takes that accompaniment to be an anti-damage motivation. The contrast between the views is only that I characterise the motivation as an experiential representation of the badness of a state of damage, whereas the putative objector characterises it as a desire for the damage to cease. But it is unclear what hangs on this difference. Indeed, on the evaluative view of desire mentioned above, the experience I am invoking is a desire-a felt, unpleasant desire-that the damage cease. I do not object to my evaluativism being put that way (see Author) ${ }^{29}$

$\operatorname{sen} \operatorname{sen} \cos c \cos 3$

29 (i) Notice the desires in question are anti-damage, not (like those Pitcher invokes) anti-pain. (ii) I have argued elsewhere that taking unpleasant pains to involve desires without evaluative content fails to accommodate their rationalising role (Author). 
In conclusion, I have defended a view on which Abe's pain is abnormal (as per the hedonic story) because he is abnormal (as per the non-hedonic story): it lacks a hedomotive component because he lacks care. Incorporated into an hedonic account, care-lack promises to explain not only Abe's failure to withdraw from visual and verbal threat, but his denial that his pain is unpleasant, and his failure to grimace, get angry, or withdraw from pain-causing stimuli; and it promises to explain this while respecting a tight link between pain's unpleasantness and motivation. To realise this promise, we need to connect care and pain's hedomotive component, and this require evaluativism. So, if evaluativism is defensible, it has a surprising virtue: being indispensable to our most promising account of asymbolia. In short, asymbolia suggests the following: contra Klein, that unpleasant pain has a composite structure and contra Klein, Grahek, and Pitcher, that the structure's hedomotive component is evaluative.

\section{REFERENCES}

Author. <Suppressed>

Berthier, M., S. Starkstein, and R. Leiguarda. 1988. "Asymbolia for Pain: A Sensory-Limbic Disconnection Syndrome", Annals of Neurology 24 (1) 41-49.

Corns, J. Forthcoming. “Unpleasantness, Motivational Oomph, and Painfulness". Mind and Language.

Cutter, B. and M. Tye. 2011. "Tracking Representationalism and the Painfulness of Pain", Philosophical Issues, 21, 90-109.

Fox, E. 2012. "Pain Asymbolia: What It Can and Can't Do for Some Philosophical Positions". Presented at the 2012 meeting of the Australasian Association of Philosophy.

Geschwind, N. 1965. "Disconnexion Syndromes in Animals and Man. Part I". Brain, 88, 237-294.

Grahek, N. 2007. Feeling Pain and Being in Pain (2 ${ }^{\text {nd }}$ edn.) (Cambridge, Mass.: MIT Press).

Hall, R. J. 2008. “If It Itches, Scratch!" Australasian Journal of Philosophy, 86, $4,525-535$.
Helm, B. 2002. "Felt Evaluations: A Theory of Pleasure and Pain", American Philosophical Quarterly, 39, 1, 13-30.

Hemphill, R. E. and E. Stengel. 1940. "A Study of Pure Word Deafness". Journal of Neurology and Psychiatry, 3(3) 251-62.

Klein, C. 2007. “An Imperative Theory of Pains". Journal of Philosophy, $104,10,517-32$

- - - 2012. "What Pain Asymbolia Really Shows". Presented at the Pain and Emotion Workshop, University of Glasgow, 30 May 2012. Currently under review.

Martínez, M. 2011. "Imperative Content and the Painfulness of Pain", Phenomenology and the Cognitive Sciences, 10, 67-90.

Nagasako, E.M., A.L. Oaklander, and R.H. Dworkin. 2003. “Congenital Insensitivity to Pain: an Update". Pain 101, 213-219.

Oddie, G. 2005. Value, Reality, and Desire (Oxford: Clarendon Press).

Pitcher, G. 1970. "Pain Perception", Philosophical Review, 79, 368-393.

Pötzl, O. and E. Stengel. 1937. "Über das Syndrom LeitungsaphasieSchmerzasymbolie". Jahrbuch der Psychiatrie 53, 174-207.

Price, D. "Psychological and Neural Mechanisms of the Affective Dimension of Pain". Science 288, 1769-1772.

Rubins, J. L. and E. D. Friedman. 1948. "Pain Asymbolia". Archives of Neurology and Psychiatry 60, 554-573.

Schilder, P. and E. Stengel. 1928 "Schmerzasymbolie". Zeitschrift für die Gesamte Neurologie und Psychiatrie 113(1), 143-158.

- - 1931. "Asymbolia For Pain". Archives of Neurology and Psychiatry 25(3), 598-600.

Stampe, D. 1987. “The Authority of Desire”, Philosophical Review, 96, 335381.

Trigg, R. 1970. Pain and Emotion (Clarendon Press: Oxford). 